\title{
The Distribution of Wealth - Growing Inequality? - A Book Review
}

\author{
Dunya Ahmed ${ }^{1} \&$ Mohamed Buheji $^{2}$ \\ ${ }^{1}$ President of - Inspiration Economy Society, Bahrain \\ ${ }^{2}$ Founder - International Institute of Inspiration Economy, Bahrain \\ Correspondence: Mohamed Buheji, President of - Inspiration Economy Society, Bahrain.
}

Received: January 26, $2018 \quad$ Accepted: February 11, $2018 \quad$ Available online: February 12, 2018

doi:10.11114/afa.v4i2.3027 URL: https://doi.org/10.11114/afa.v4i2.3027

\section{Michael, S. Mike, P., \& King, J. E. (2016). The Distribution of Wealth - Growing Inequality?}

This book uses data from 21 countries to illustrate the distribution of wealth in capital economies that is far from being fare and equality. However, it is a book that is focused on western countries and very focused on one part of the world only.

Schneider et. Al (2016) shown in this work how wealth in this world is distributed statistically, historically and geographically. The book explains the basics of why is the distribution of wealth important and how can it be measured which established an important basis for the beginners and different discipline researchers in the field.

Schneider et. Al (2016) managed to show how unequal is the wealth distribution in practice and how its inequality has even changed over time. The authors gone also into defining what factors determine the level of inequality and what are details criteria's that can be used to rank alternative distributions of wealth. The book listed the type of instruments that are available to a government that wishes to change the distribution of wealth.

Technical details as the distribution of wealth related to the aggregate amount of wealth and extent of this wealth linked to other things as economic, political and social factors; were also covered by the authors.

In addition, the book emphasis that inequality increased in most countries since 1970. This alarming facts call for more efforts from all socio-economic leaders, practitioners, change agents and researchers; although this increase in inequality may be due that it is easier to measure and get statistics. The book tries to show alternative ways in measuring and understanding wealth, but again all from capitalism point of view. Authors try to prove that inequality has increased in recent time and with changing policies economic situation can be changed. However, this explanation is totally different from new democratic economies such as inspiration economy, creative economy and knowledge economy which might close the inequality gap with less resources, by capitalizing on the different humans and society intrinsic power.

The book even though is very useful for all those whom want to understand the basis of wealth in any economy, didn't consider effectively the wealth from the socio-economic perspective, despite mentioning issues as inheritance, gender and ethnicity. Even though the authors explained what are the actual, estimated and ideal wealth, we believe that in reality there are no ideal, each distribution has its positivity and negativity, moreover, goodwill cannot be measured in measuring wealth in normal way. The authors of the book tackled wealth from capitalism point of view and never tried to discuss the intrinsic wealth that comes from the new democratic economies as Inspiration Economy, Knowledge Economy, Innovation Economy, Creativity Economy and even mostl recent Resilience Economy. We believe all these economies need to be invistigated in relevance to exploration and distribution of wealth too.

Even though the book have technical details and lots of tables that illustrate the historic changes that could be presented presented more friendly non-economists using diagrams of infographics, they authors managed to emphasised their perspective of inequal distribution of wealth through such statistics. It is worth finally to say that Schneider et. Al (2016) team shown clearly how affluence and well-being depends only on the fraction of the social cake, as it depends on social alia. We believe that this book carried distinguishing statics that link between risk and distribution of property, besides other important information on the dynamics of wealth in relation to GDP.

\section{Copyrights}

Copyright for this article is retained by the author(s), with first publication rights granted to the journal.

This is an open-access article distributed under the terms and conditions of the Creative Commons Attribution license which permits unrestricted use, distribution, and reproduction in any medium, provided the original work is properly cited. 